\title{
Have Filipino Households Become Less Prudent?
}

\section{Akiko Terada-Hagiwara*}

November 4, 2010

June 9, 2011

This version: September 9, 2011

\begin{abstract}
Throughout the 2000s, the average household saving rate in the Philippines declined sharply. This paper explains why households' consumption growth has been higher than income growth during this period. Tracing cohorts shows that saving declined across all demographic groups. A test that provides the strength of the precautionary saving motive yields a plausible explanation that households have become financially constrained and less prudent in the recent years. This paper argues that these patterns are best explained by the extended coverage of social security system particularly to informal sector employees during the 1990s in the Philippines.
\end{abstract}

\footnotetext{
* Asian Development Bank; 6 ADB Avenue, Mandaluyong City 1550, Philippines; Tel (632) 632 5587, Fax (632) 636 2342; ahagiwara@adb.org.

This paper has benefited from comments from seminar participants at the Institute of Social and Economic Research, Osaka University and 12th International Convention of the East Asian Economic Association, Korea. The author appreciates the help of Charles Y. Horioka, Eswar Prasad, and Shikha Jha for useful discussions at different stages of the paper, and Shiela Caming, Aleli Rosario and Pilipinas Quising for capable research assistance. However, the author is solely responsible for any remaining errors.
} 


\section{Introduction}

From 1994 to 2006, the average household saving rate in the Philippines declined by 5.2 percentage points to about mere $5 \%$ of disposable income. The Philippines provides an excellent laboratory to study the determinants of household saving for its dynamic developments in determining factors over the decade.

First, real GDP growth rate had undergone a transition from relatively steady growth in the 1960s and 1970s to sharp fluctuations in the 1980s and 1990s. The older cohorts enjoyed higher and steadier economic growth, while those relatively younger cohorts lived under relatively volatile economic situation. The second feature of the Philippines that is relevant to life-cycle saving is its demographic change over the last several decades. The age distribution of the population has been sharply skewed toward the younger population. Third, the nation's social security system had evolved quite rapidly during the 1990s, which would affect the consumption and saving behavior significantly. An evolving social security system, stagnant economic growth, declining yet still high population growth, and fertility rate all have consequences for saving rate.

This paper contributes to the literature by arguing that the usual suspects-rising youth dependency and stagnant income growth—are not sufficient to explain the observed declining trend in the Philippines as suggested such as by Bersales and Mapa (2006). This paper is the first to show that the declining saving rate has been 
due to the reduced precautionary motives as partly expected by developments such as the expansion of the social security system. More extensive coverage of the system to the informal sector employees appears to have reduced households' precautionary savings, which has been magnified by the slow income growth.

In order to arrive at this conclusion, we first show that the declining trend remains even after controlling for the demographic variables. Also, the declining trend cannot be simply due to the aggregate macroeconomic shocks as suspected. Liquidity constraint and precautionary behavior are then considered to show how they affect saving rates of Filipino households over time. Additionally, this paper finds that the Filipino age-saving rate profile fits in the standard life cycle hypothesis showing a hump-shaped age-saving rate profile, once controlled for the demographic shifts and family composition.

The paper is organized as follows. Section II describes the survey data and provides some stylized facts on the saving behaviors of Filipino households. Section III adapts a decomposition analysis to argue that the demographic changes are not sufficient to explain the declining saving rate. In Section IV, we introduce uncertainty in consumption to test for precautionary motives. Changing precautionary motives would explain the downward time-saving rate profile. The final section concludes.

\section{The Survey Data and Stylized Facts}




\section{A. The Survey Data}

We use household income and expenditure surveys (FIES)—from 1988 through 2009. In the Philippines, FIES is conducted every three years, and a total of eight survey results are available over this period. 'We measure saving as the difference between disposable income and total (and non-durable) consumption expenditures. The measure of disposable income that we focus on includes agricultural and nonagricultural salaries and wages from regular employment, net share of crops, cash receipts, and other assistance from both overseas and domestic sources. Interest, pension and social security benefits, and dividends from investment are also included. Taxes are excluded. ${ }^{\text {ii }}$

\section{B. Puzzle on Declining Household Saving Rate}

Demographic development has been cited as one of the factors to explain the declining saving trend in the Philippines. group would have increased the education and health expenditures, which could result in lower aggregate saving.

For most of the interesting questions about saving and the life cycle, it is necessary to track individuals over time, and to observe the changes in consumption, income, and saving as people age. Although we cannot track individual households in the data, we can track cohorts of households, with cohorts defined according to their year of birth. With the FIES data, we can follow cohort means for 1988 to 2009 . 
Figure 1 shows how the cohort grouping can be used to show both the life cycle pattern of family formation and the cohort effects of increasing fertility. The age of the head of the household is plotted on the horizontal axis, while the vertical axis shows the average number of children in the household. Children here are defined those under age 25. The plotted points are connected when we follow the same cohort through time, but different cohorts are left unconnected. To avoid clutter, we show only every tenth cohort, so that the first segment on the left hand side of the figure shows the number of children in households headed by those who were 25 in 1965. By the time these people are 35 in 1975, they are well launched into their child-bearing years, and have 3.5 children on average. The peak comes when the heads' age is about mid-40s with about 4.5 children on average. The falling fertility shows up in the profiles as we move from one cohort to the next.

\section{$<$ Insert Figure 1 here>}

To gauge the time series characteristics of the household saving behavior, Figure 2 plots income and consumption against the age of the household head, with each panel corresponding to a different cohort. Many cohorts experienced a sharp increase and drop in income and consumption-the observation shared across different cohorts. Most notably, those cohorts of 1960 or later are found to save much less than older cohorts regardless of their age. This finding suggests an importance of time effects in consumption and saving behaviors. In the next section, we will show that controlling for demographic effects do not provide an answer to the 
declining saving rate.

$<$ Insert Figure 2 here>

\section{Controlling for Demographic Effects on Household Saving Rates: A Decomposition Analysis}

The Philippines, like many other countries, is undergoing a major demographic transition. Hence, a careful analysis of demographic factors seems warranted in accounting for the observed saving behavior. Moreover, different age and cohort groups are likely to have very different saving behavior and these are likely to change. It is therefore necessary to separate age, cohort, and time effects to more clearly characterize the effects of demographic variation on changes in saving patterns.

\section{A. Decomposition Methodology}

With no income uncertainty, the consumer has cash assets $A_{t}$, so that looking ahead $T$ periods, there is a budget constraint

$\sum_{t=1}^{T}(1+r)^{-1} c_{t+1}=W_{t}=A_{t}+\sum_{t=1}^{T}(1+r)^{-1} y_{t+1}$

where $c_{t}$ is household's consumption, $r$ is interest rate, $y$ is disposable income. A life cycle model without uncertainty predicts that consumption is a function of resources 
(earnings plus inherited assets), with the constant of proportionality depending on the household head and the real interest rate. Given $1 / T$ is a function of age, the consumption can be expressed as follows:

$c_{h a}=f_{h}(a) W_{h}$

where $c_{h a}$ denotes the consumption of household $h$ headed by an individual of age $a$ and with lifetime resources $W_{h}$. This equation holds at the level of the individual, but given its additive structure, after taking logs, it can be averaged over all households of the same age as defined by the head's age in each year, $t$, which yields the following expression.

$\overline{\ln c_{a t}}=\overline{\ln f(a)}+\overline{\ln W_{b}}$

This treatment allows us to decompose into a wealth term, which is regarded constant within cohorts, and an age term. The age effects $\overline{\ln f(a)}$ are captured by a vector of age dummies, and the lifetime resources $\frac{}{\ln W_{b}}$ by a vector of cohort (year of birth) and time dummies. Deaton and Paxson (1994) considered additional time effects to account for the presence of macroeconomic effects, which cannot be explained by cohort or age effects. The life cycle model with uncertainty provides some basis to have time effects once uncertainty is admitted as wealth levels will be revised in response to macroeconomic shocks. The issue of uncertainty is looked at more closely in the next section. A decomposition follows a simple formula as 
follows:

$\overline{\ln c_{a t}}=D^{a} \alpha_{c}+D^{b} \gamma_{c}+D^{t} \theta_{c}+\varepsilon_{c}$

where $D^{a}, D^{b}$, and $D^{t}$ are matrices of age, year of birth, and year dummies, $\alpha_{c}{ }^{\prime} \gamma_{c}$ ' and $\theta_{c}$ are the corresponding age, cohort, and year effects on consumption, and ${ }_{\varepsilon_{c}}$ is the error term. ${ }^{\text {iv } v}$

Following equation (1), income is similarly estimated using an equation analogous to the one for consumption. ${ }^{\mathrm{vi}}$

$\overline{\ln y_{a t}}=D^{a} \alpha_{y}+D^{b} \gamma_{y}+D^{t} \theta_{y}+\varepsilon_{y}$

where $D^{a}, D^{b}$, and $D^{t}$ are matrices of age, year of birth, and year dummies as in equation (2), $\alpha_{y}{ }^{\prime} \gamma_{y}$, and $\theta_{y}$ are the corresponding age, cohort, and year effects on income, and $\varepsilon_{y}$ is the error term. Saving ratio is measured based on the estimated equations as the difference of the logarithms of income and consumption, or the equation (2)-(3).

\section{B. Decomposition Results}

Figure 3 show the estimated age, cohort, and time profiles of income, consumption, and saving rates. When estimating these equations, we also include demographic 
controls, such as log (family size), log (employed members), and the share of individuals in the household aged 1-6, 7-14, 15-24, and 25 and above. vii

The age effects show that the saving rate starts to fall slightly earlier than the standard retirement age of sixty in the Philippines unlike the monotonically increasing saving rate with age that the unconditional mean suggests. ${ }^{\text {viii }}$ This result can be attributed to the controls that are included-the share of different age family members. The age-saving profile becomes hump-shaped as shown in Figure 3. The saving rate reaches its peak at the household head's age of about mid-50s, and its trough before the head reaches age 30 and again close to age 70 . This result suggests that saving rate is lowest when household heads' age is about 40 because the children's education and associated costs are highest around this time. ${ }^{\text {ix }}$

The cohort profile of income, consumption, and saving suggest that younger and older cohorts had relatively higher income than those who were in their mid-50s in 1988. The resulting effect on savings suggests that the higher saving cohorts are older cohorts-those that were in their mid-60s in 1988-saving about 2-3 percentage points more than earlier cohorts, which may be capturing the fact that those cohorts were unscathed by the economic downturns of the early 1980 s and late 1990s.

Finally, we turn to the time profile. The time effects explain more than 7 percentage points decrease in the saving rate from 1988 to 2009. Given the fact that 
demographic characteristics are already controlled for, this is a significant number suggesting a limited role for demographic changes in explaining the decline in Filipino household savings over the last two decades. This result is robust to alternative definition of the saving rate such as total household income minus total household expenditure that Bersales and Mapa (2006) uses.

Either aggregate macroeconomic or institutional shifts explain the declining saving rate. One factor might be a higher inflation rate in the 2000 s driven mainly by a hike in oil and food prices, and/or negative real interest rate. Alternatively, the saving behavior might have been affected by a shift in a precautionary motive of Filipino households, as also suggested from the cohort effects. These uncertainty and time series factors are investigated further in the next section.

$<$ Insert Figure 3 here>

\section{Precautionary Motive with Uncertainty in Consumption}

Given the importance of the uncertainty as suggested in the previous sections, theories of precautionary saving have intuitive appeal and important implications. Deaton (1992) emphasizes that uncertainty may substantially alter consumers' behavior. ${ }^{\mathrm{x}}$ Since demographic shifts do not seem to be able to account for the decline in household saving rate with time, we now discuss an alternative hypothesis that could account for the declining time-saving rate profile. As suggested in the 
previous section, we investigate if there has been a role in the precautionary motive in the Filipino households and how macroeconomic developments affected the behavior. One would expect a declining saving rate over time if the household saving behavior has been less prudent in the recent years.

A number of factors are relevant in affecting the precautionary motive of the Filipino households. First, the Philippines' Social Security System developed significantly during the 1990s. Existing studies found that coverage by social programs, such as disability insurance, unemployment insurance, and health insurance, is negatively associated with saving. In fact, the coverage of the system, which covers contingencies such as disability, health, and old age, had been extended intensively. ${ }^{\mathrm{xi}}$ In 1988, only less than half of the Filipino workers were covered in the system. After the coverage was extended to include non-working spouses, selfemployed workers and agricultural workers in the 1990s, the system now covers 3 out of every 4 workers. Household helpers and informal sector workers who earn at least 1,000 pesos a month were also included by mid-1990s. This expanded coverage of the social security system implies a reduced need for younger cohorts to accumulate precautionary savings.

That saving provides insurance for future contingencies has long been recognized in literature, but this precautionary motive has played a minor role in the empirical investigation of the household saving behavior in general, and Filipino households in particular. ${ }^{\text {xii }}$ Because of the significant development such as in the social security 
system in the Philippines, we estimate relative prudence considering the liquidity constraints in this section.

\section{A. Estimation Methodology}

The empirical framework follows Zeldes (1989), where the Lagrange multiplier associated with the liquidity constraint is added to the consumption Euler equation.

$U^{\prime}\left(c_{i, t}\right)=\left(\frac{1+r}{1+\delta}\right) E_{t}\left[U^{\prime}\left(c_{i, t+1}\right)\right]+\lambda_{i, t}$,

where $\delta$ is discount rate, and $E_{t}$ is the conditional expectation operator, is the Lagrange multiplier associated with the liquidity constraint. This condition shows that greater uncertainty is linked to greater saving when the third derivative of utility is positive. An increase in uncertainty raises the expected variance of consumption, which in turn implies higher expected marginal utility when marginal utility is convex.

Taking the second-order Taylor approximation of $E_{t}\left[U^{\prime}\left(c_{i, t+1}\right)\right]$ around $c_{i, t}$ yields the consumption growth equation as follows.

$E_{t}\left(\frac{c_{i, t+1}-c_{i, t}}{c_{i, t}}\right)=\frac{1}{\sigma}\left(\frac{r-\delta}{1+r}\right)+\frac{\rho}{2} E_{t}\left[\left(\frac{c_{i, t+1}-c_{i, t}}{c_{i, t}}\right)^{2}\right]+\tilde{\lambda}_{i, t}$,

where $\sigma$ is the coefficient of relative risk aversion, $-\frac{U^{\prime \prime} c_{i, t}}{U^{\prime}} ; \rho$ is the coefficient of 
relative prudence, $-\frac{U^{\prime \prime \prime} c_{i, t}}{U^{\prime \prime}}$; and $\tilde{\lambda}_{i, t} \equiv-\left(\frac{1+\delta}{1+r}\right) \frac{\lambda_{i, t}}{c_{i, t} U^{\prime \prime}} \cdot \tilde{\lambda}>0$ for the liquidityconstrained households in equation (4). If $\rho$ is positive, then higher expected consumption growth (which reflects higher saving) is associated with higher expected squared consumption. ${ }^{\text {xiii }}$

Having panel data to test this hypothesis is ideal—however, FIES does not provide the panel data. We therefore follow Deaton (1985) to form time series data from the cross sectional data that we examine from the FIES. Corresponding to individual behavior, a cohort version of the relationship of the same form exists, but "with cohort" means replacing individual observations. We eliminate the cohorts that do not exist for all eight surveys (1988-2009). As a result, the sample of this section has 25 cohorts from 11 regions in the Philippines. Those cohorts include the heads who were born from 1939 to 1963 . $^{\text {iv }}$ We restrict the sample to households whose head is $25-70$ years old. Again, each observation in this regression is weighted by the square root of the number of original observations that its average is based on. Figure 4 shows box plots of the squared consumption growth by year. The degree of dispersion and median value of the squared consumption growth—uncertainty measure-have been reduced steadily over time as we expect. A notable exception is 1997 possibly affected by the Asian financial crisis.

Estimation specification uses an initial income as a proxy for $\tilde{\lambda}$. 


$$
\frac{1}{N} \sum_{t=1}^{N}\left(\frac{c_{i, t+1}-c_{i, t}}{c_{i, t}}\right)=\beta_{0}+\beta_{1} \frac{1}{N} \sum_{t=1}^{N}\left(\frac{c_{i, t+1}-c_{i, t}}{c_{i, t}}\right)^{2}+\beta_{2} y_{i, 0}+\eta_{i},
$$

where $\beta_{0}=\frac{1}{\sigma}\left(\frac{r-\delta}{1+r}\right), \beta_{1}=\frac{\rho}{2}, N$ represents the number of periods, $y_{i, 0}$ is the initial income, and $\eta_{i}$ is the expectation error. The size of $\rho$ determines the strength of the precautionary saving motive. We expect $\beta_{2}<0$ for the constrained and $\beta_{2}=0$ for the unconstrained. We use the instrumental variable technique. Squared consumption growth, which is a proxy variable for uncertainty, is instrumented with the household head's education and share of income from agriculture sector. Income growth and demographic variables, i.e. share of individuals in the household aged 1-6, 7-14, 15-24, and 25 and above are also included. Cohort dummy variables enter as a taste shifter, and macroeconomic developments are controlled by real interest rate. ${ }^{x v}$ The uncertainty variable is Interacted with various variables such as dummy variables for different sub-periods, household heads' job category, and income group, and included in regressions one by one to examine if each subgroup and/or -period has additional effects on the consumption growth and hence the saving rate.

\section{B. Estimation Results}

Table 1 columns $A$ to $C$ show results of instrumental variable estimation with and without the interacted variables with sub-period dummies. The results are interesting 
and intuitive suggesting an important role played by the precautionary motive in the Filipino households' consumption behavior. The first stage results are shown in the lower part of the columns for all the estimation results, and generally plausible. Engoneniety test results suggest that the instrumental variable estimation is consistent while the underidentification test results indicate that the equations are identified. Test for weak instruments is also conducted. The Wald F statistics suggest that the null hypothesis of weak instruments can be mostly rejected at $10 \%$,

\section{B.1. Estimation Results: overall vs 2000s}

The estimated coefficients on the squared consumption growth for the entire sample reveal that risk affects consumption positively and significantly. The estimation result for the entire sample in the column A shows a significant role played by the uncertainty with its coefficient being 2.03 and significant on the consumption growth. This is what precautionary hypothesis predicts: households that face more risks save more. The estimated strength of the precautionary motive also appears to be significant and plausible in magnitude. ${ }^{\text {xvi }}$ Since income growth and demographic variables are also controlled for, this result contributes to the literature by arguing that the usual suspects—rising youth dependency and stagnant income growth—are not sufficient to explain the observed declining trend in the Philippines as widely suggested in the existing literature.

The interactive variable with the dummy for the 2000 s is then included to investigate 
if there has been a shift in precautionary motive in Filipino households. The results are interesting and intuitive. This precautionary motive disappeared in the 2000 s as shown in the columns $B$ and $C$, which include the interactive variables with subsample dummies for the 2000 s and the years after 2003. The estimated coefficients on the interacted variables are significant and negative in both cases leading the net effects of the uncertainty variable to be insignificantly different from zero showing no sign of prudence.

Our empirical results are consistent with studies that have found that coverage by social programs, such as disability insurance (Kantor and Fishback, 1996), unemployment insurance (Engen and Gruber, 2001), and Medicaid (Gruber and Yelowitz, 1999) in the US, and health insurance (Chou et al, 2003) in Taipei,China, are negatively associated with saving.

\section{<Insert Table 1 here>}

\section{B.2. Estimation Results: overall vs households with informal sector jobs}

In the next stage, we examine if this changing behavior in the 2000 s is associated with the extended coverage of the social security system to informal sector workers. The informal sector jobs are defined as those the Social Security System was extended during the 1990s, which include self employed workers, workers in private households, and employers and employees of own family-operated farms and businesses. Households that are categorized to have the informal sector jobs 
consist a half of the surveyed households.

Columns A, B, and C of Table 2 show the results including the interacted variables for informal sector jobs. Interestingly, simply having an informal sector job would not lead to become less prudent, and does not have significant additional impacts on the consumption behavior. Households are generally prudent as reported in column A. However, being in informal sector starts to matter in the 2000s with the significant negative coefficient, -0.81 , on the uncertainty variable as reported in column $\mathrm{B}$. This impact can be understood as a possible significant impact arising from the extended Social Security System consistent with our prior. ${ }^{\text {xvii }}$

\section{$<$ Insert Table 2 here}

\section{B.3. Estimation Results: Low versus High income}

Further, we test the assumption of constant absolute prudence imposed in equation

(5) above- how low-income consumers react differently to the factors affecting the uncertainty. Kimball (1990) suggests that prudence, like risk aversion, is likely to decline with wealth suggesting that lower-income people will be more sensitive to the risk reductions, that is, the wider coverage of social security system will have a larger impact on their precautionary saving and consumption.

An estimation exercise is conducted including an interactive variable for the poor households with informal sectors jobs in 2000s. The poor households are defined as 
those below the median income. The estimation result in column $\mathrm{C}$ supports the claim with the significantly negative coefficient, -1.67-much larger (in absolute term) than that with all the income groups considered. When the definition of the poor changed to those below income of $25 \%$ of the sample, the absolute value of the coefficient (not reported) is even larger (-2.82). ${ }^{\text {xviii }}$ The result indicates that the impact from the extension of social security system is particularly large for the lower income households validating the claim made by Kimball (1990) among others.

Other variables included in the estimation exercise are generally consistent. The estimated coefficients on the interest rate terms are negative consistent with the prior that the higher interest rate slows consumption growth. Coefficient on income growth is positive and significant in all cases validating its importance. The contraction in the average household income in the 2000s has been contributing to the slowing consumption growth. Although not reported here to save space, two of the demographic variables significantly explain the consumption growth-positive for the share of individuals in the household aged 1 and below. The coefficient on initial income is mostly positive or insignificant while we expect that the coefficient to be negative when households are financially constrained. This result is not affected even when different wealth measure is included. ${ }^{\text {xix }}$ One possible reason for this result is a habit formation, which implies that consumption reacts slowly to declining income explaining the initial income affecting consumption growth positively.

\section{Concluding Remarks}


This paper explains why the average household saving rate in the Philippines declined substantially in the 2000s. Contrary to what was generally believed, our decomposition analysis suggests that demographic factors do not fully explain the declining time-saving rate profile. On the other hand, we find that the declining saving rate is associated with the changing precautionary motives of Filipino households.

We find that the precautionary saving was strong in the 1990s when the coverage of the social security system was still limited. However, the precautionary motive does not seem to be present in the 2000s. The less prudent behaviors are found to be significant with households with informal sector jobs, but only in the 2000s validating the extended social security system being the major factor affecting the Filipino households saving behavior. Moreover, this impact is found particularly strong with lower income households in the 2000s. Our evidence supports the contention that precautionary motives, particularly of low-income households, are an important determinant of saving. 


\section{Endnotes}

${ }^{\mathrm{i}}$ The eight surveys were conducted consistently using the same survey and sampling designs. For details, see Appendix 1 of Terada-Hagiwara (2009).

ii The tax rate is slightly higher for high income households averaging at $1.4 \%$ (of total income) as compared with $0.8 \%$ for relatively low income group. Though taxes can affect consumption behavior differently across different income groups, the results of our analyses are not affected by the definition used possibly due to the marginal difference in the tax rates.

iiiBersales and Mapa (2006) analyze the same survey (up to 2003) and report that the declining trend has to do with the higher proportion of young dependents in the economy.

iv Each observation in this regression is weighted by the square root of the number of original observations that its average is based on. To exclude unreliable observations, the observations are dropped when the number of original observations is less than 300 per each cohort.

${ }^{v}$ Deaton and Paxson (1994) identify age and cohort effects by imposing a constraint that the year effects must add up to zero and be orthogonal to a time trend. This constraint forces the decomposition to attribute the rising income and consumption to age and cohort effects, not to time. In the case of the Philippines, the country experienced macroeconomic fluctuations during the sample period, unlike Taipei,China as in Deaton and Paxson (1994), where positive GDP growth was steadily recorded during the period. Thus, it is more appropriate to identify time effect arising from the macroeconomic fluctuations by imposing constraint on the cohort effects in the case of the Philippines.

${ }^{v i}$ Chamon and Prasad (2008) argue that to the extent the age profile of income is invariant to economic growth, then income can also be expressed as a function of age and lifetime resources.

vii In this exercise, we take our baseline household as one whose head was 25 years old in 1988 . For example, the age profile shows how income and consumption would vary with age, holding the cohort effect constant at the level for the cohort born in 1963 and the year effect at its 1988 level. Similarly, the cohort profile shows how income and consumption would vary with year of birth, holding constant the age effect at its level for 25-year olds and the year effect at its 1988 level. Finally, the year profile shows the variation over time holding constant the age effect at its level for 25-year olds and the cohort effect at the level of those born in 1963.

viii In fact, the flow of saving should not only decline after retirement but should become negative. This is not visible in this exercise since there are more than one employed members in the households with the age of the head beyond the normal retirement age of 60 . See detailed discussion in TeradaHagiwara (2009).

${ }^{\mathrm{ix}}$ The result holds when we use non-durable consumption instead of the total expenditure.

${ }^{x}$ Skinner (1988) derives an approximation for optimal life cycle consumption that implies that, with plausible amounts of income uncertainty and risk aversion, precautionary saving is more than half of total life cycle saving.

${ }^{x i}$ As part of the Employees' Compensation Program in 1992, coverage was extended for selfemployed workers. In January 1992, compulsory coverage of self-employed farmers and fishermen earning at least $\mathrm{P} 1,500$ per month or $\mathrm{P} 18,000$ per annum was initiated. Later in the year, voluntary coverage was extended for non-working spouses of Social Security System members (RA 7192 Women in Nation-Building Act). In 1993, compulsory coverage included household helpers earning at least P1,000 a month. In 1995, voluntary coverage was expanded to overseas contract workers and self-employed persons with a monthly net income of at least $\mathrm{P} 1,000$. In 1997, expanded compulsory coverage included self-employed workers and agricultural workers who are not paid any regular daily wage or who do not work an uninterrupted period of at least 6 months, household helpers, parents employed by children, and minors employed by parents.

${ }^{x i i}$ Chou et al. (2003) provides a survey of past theoretical and empirical literature on the issue. 
xiii This condition holds for the constant risk aversion utility function and the constant absolute risk aversion function, but does not hold for quadratic utility, by which consumers' utility is affected by the presence of uncertainty, but their behavior does not change in response to it.

${ }^{x i v}$ Durable expenditures are excluded from the analysis because they affect utility for more than one quarter, violating the assumption that utility is time separable.

${ }^{x v}$ A dummy variable for 1997, which would potentially capture the effects of Asian financial crisis, was also added. The coefficient on the dummy variable was insignificant and did not affect the results. The dummy variable was not included in the estimations reported in the paper.

${ }^{x v i}$ Mehra and Prescott (1985) cite a variety of studies that conclude that the coefficient of relative risk aversion is at least one, and their own analysis of the historical risk equity premium implies that the coefficient must be much larger than 10 . The constant relative risk aversion (CRRA) utility would imply the size of prudence to vary between 2 and 5 corresponding to the coefficient ranging from 1 to 4.

xvii Manasan (2009) reports that only about $30 \%$ or 8 millions are contributing members as of total 27.2 million that are covered by the Social Security System. Despite the still limited share of contributing members, the expansion of the Social Security System to cover previously excluded population seemed to have a significant impact on their behavior-informal sector households are becoming less prudent over time, which is our focus.

xviii Comparable studies for developing countries are still limited, but the result is consistent with Chou et al. (2003), which shows that the absolute prudence of the lowest income quantile is almost twice as large as the one immediately above quantile.

xix The measure tried includes rental from non-agricultural lands, buildings, other properties, and interest from bank deposits and loans to other households. 


\section{References}

Bersales, Lisa Grace and Dennis Mapa. 2006. Patterns and Determinants of Household Saving In the Philippines. Report prepared under the EMERGE Project of USAID. Available:

www.stat.upd.edu.ph/ARTICLES/Article3/Paper_BERSALES_MAPA.pdf.

Chamon, M. and E. Prasad. 2008. "Why Are Saving Rates of Urban Households in China Rising." NBER Working Paper 14546. National Bureau of Economic Research. Cambridge, Massachusetts:

Chou, Shin-Yi, Jin-Tan Liu, and James K. Hammitt, 2003. "National Health Insurance and precautionary saving: evidence from Taiwan." Journal of Public Economics 87(2003): 1873-1894.

Deaton, Angus. 1985. "Panel Data from Time Series of Cross-Sections." Journal of Econometrics 30(1985): 109-126.

Deaton, Angus. 1992. “Understanding Consumption." Clarendon Lectures in Economics. New York: Oxford University Press Inc.

Deaton, Angus and Christiana Paxson. 1994. "Saving, Growth, and Aging in Taiwan." Studies in the Economics of Aging. National Bureau of Economic Research Project Report Series. Chicago and London: University of Chicago Press.

Dynan, Karen. 1993. "How prudent are consumers?" Journal of Political Economy 101: 1104-1113.

Engen, E.M. and J. Gruber. 2001. "Unemployment insurance and precautionary saving." Journal of Monetary Economics 47 (3): 545-579. 
Gruber, J. and A. Yelowitz. 1999. "Public health insurance and private savings." Journal of Political Economy 107 (6): 1249-1274.

Kantor, S.E. and P.V. Fishback. 1996. "Precautionary saving, insurance, and the origins of workers compensation." Journal of Political Economy 104 (2): 419442.

Kimball, Miles, 1990. "Precautionary Saving in the Small and in the Large," Econometrica 58, (1) (Jan., 1990): pp 53-73.

Manasan, Rosario G. 2009. "Social insurance in the Philippines: responding to the global financial crisis and beyond." Philippines Institute for Development Studies Discussion Paper 2009-03. Manila.

Mehra, Rajnish, and Edward C. Prescott. "The Equity Premium: A Puzzle." Journal of Monetary Economics 15 (March 1985): 145-161.

Skinner, Jonathan. 1988. "Risky Income, Life Cycle Consumption, and Precautionary Savings." Journal of Monetary Economics 22 (September 1988): 237-255.

Terada-Hagiwara, A. 2009. "Explaining Filipino Households' Declining Saving Rate." ADB Economics Working Paper Series, No. 178. Manila.

Zeldes, Stephen P. 1989. "Consumption and liquidity constraints: an empirical investigation." Journal of Political Economy 97: 305-346. 
Table 1: IV Estimation Result: Consumption Growth

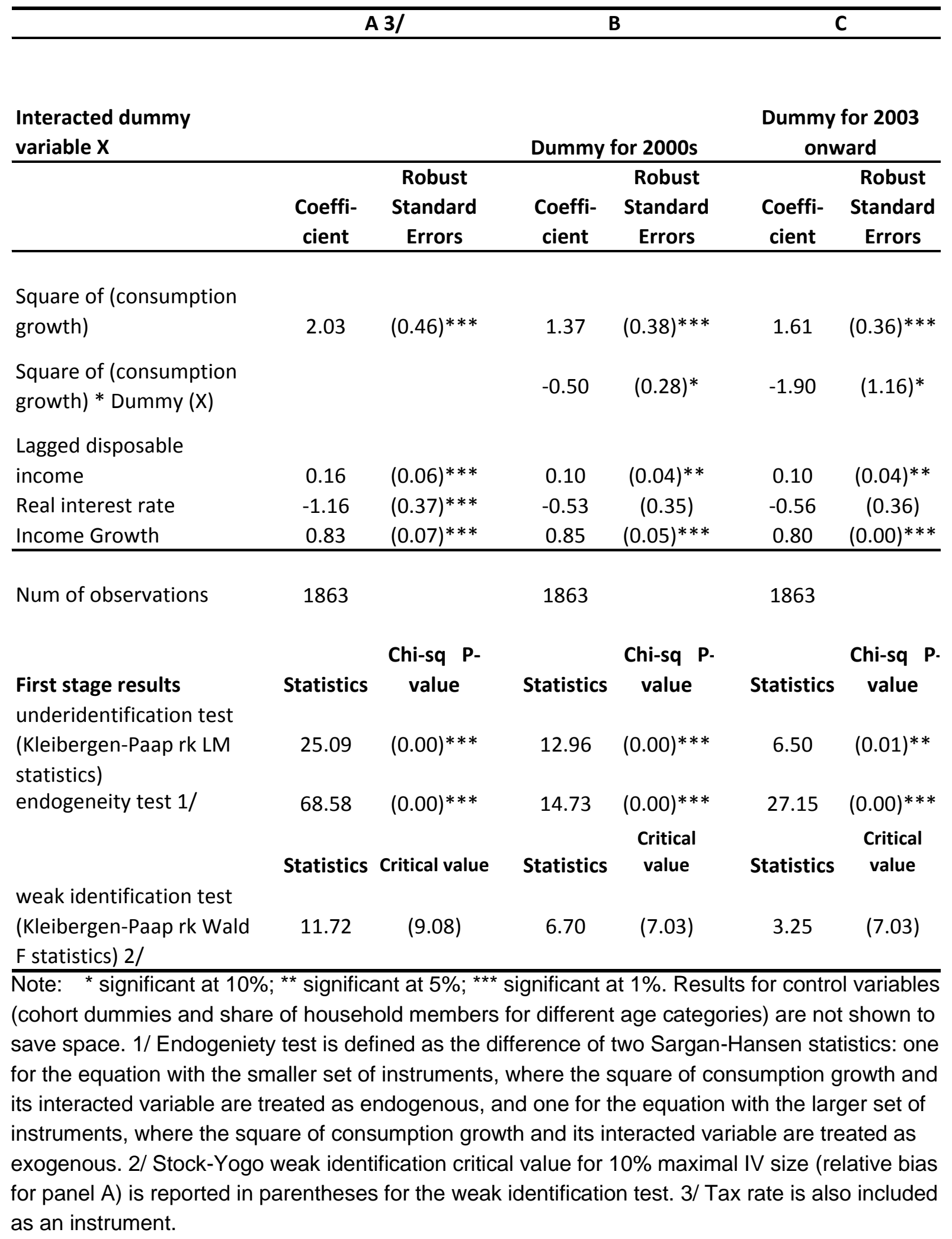


Table 2: IV Estimation Result: Households with informal sector jobs

\begin{tabular}{|c|c|c|c|c|c|c|}
\hline \multirow{3}{*}{$\begin{array}{l}\text { Interacted dummy } \\
\text { variable X }\end{array}$} & \multicolumn{2}{|c|}{ A } & \multicolumn{2}{|c|}{ B } & \multicolumn{2}{|c|}{$\mathbf{C}$} \\
\hline & \multicolumn{2}{|c|}{$\begin{array}{c}\text { Dummy for HHs } \\
\text { with informal sector } \\
\text { jobs }\end{array}$} & \multicolumn{2}{|c|}{$\begin{array}{c}\text { Dummy for HHs } \\
\text { with informal } \\
\text { sector jobs in the } \\
2000 \text { s }\end{array}$} & \multicolumn{2}{|c|}{$\begin{array}{l}\text { Dummy for poor } \\
\text { HHs with informal } \\
\text { sector jobs in the } \\
2000 \text { s }\end{array}$} \\
\hline & $\begin{array}{l}\text { Coeffi- } \\
\text { cient }\end{array}$ & $\begin{array}{c}\text { Robust } \\
\text { Standard } \\
\text { Errors } \\
\end{array}$ & $\begin{array}{c}\text { Coeffi- } \\
\text { cient }\end{array}$ & $\begin{array}{c}\text { Robust } \\
\text { Standard } \\
\text { Errors } \\
\end{array}$ & $\begin{array}{c}\text { Coeffi- } \\
\text { cient }\end{array}$ & $\begin{array}{c}\text { Robust } \\
\text { Standard } \\
\text { Errors } \\
\end{array}$ \\
\hline $\begin{array}{l}\text { Square of (consumption } \\
\text { growth) }\end{array}$ & 3.58 & $(1.35)^{* *}$ & 1.41 & $(0.38) * * *$ & 1.57 & $(0.36)^{* * *}$ \\
\hline $\begin{array}{l}\text { Square of (consumption } \\
\text { growth) * Dummy (X) }\end{array}$ & -3.42 & $(2.35)$ & -0.81 & $(0.46)^{*}$ & -1.67 & $(0.95)^{*}$ \\
\hline Lagged income & 0.07 & $(0.06)$ & 0.10 & $(0.05)^{* *}$ & 0.05 & $(0.06)$ \\
\hline Real interest rate & -0.75 & $(0.33)^{* *}$ & -0.53 & $(0.36)$ & -0.45 & $(0.40)$ \\
\hline Income Growth & 0.80 & $(0.06)^{* * *}$ & 0.84 & $(0.05)^{* * *}$ & 0.72 & $(0.09)^{*}$ \\
\hline Num of observations & 1863 & & 1863 & & 1863 & \\
\hline $\begin{array}{l}\text { First stage results } \\
\text { underidentification test }\end{array}$ & Statistics & $\begin{array}{l}\text { Chi-sq } P \text { - } \\
\text { value }\end{array}$ & Statistics & $\begin{array}{l}\text { Chi-sq } P \text {. } \\
\text { value }\end{array}$ & Statistics & $\begin{array}{l}\text { Chi-sq } P \text {. } \\
\text { value }\end{array}$ \\
\hline $\begin{array}{l}\text { (Kleibergen-Paap rk LM } \\
\text { statistics) }\end{array}$ & 21.67 & $(0.00)^{* * *}$ & 13.89 & $(0.00)^{* * *}$ & 12.31 & $(0.00)^{* * *}$ \\
\hline endogeneity test 1 / & 30.27 & $(0.00)^{* * *}$ & 16.10 & $(0.00)^{* * *}$ & 21.97 & $(0.00)^{* * *}$ \\
\hline & Statistics & $\begin{array}{l}\text { Critical } \\
\text { value }\end{array}$ & Statistics & $\begin{array}{l}\text { Critical } \\
\text { value }\end{array}$ & Statistics & $\begin{array}{l}\text { Critical } \\
\text { value }\end{array}$ \\
\hline $\begin{array}{l}\text { weak identification test } \\
\text { (Kleibergen-Paap rk Wald } \\
\text { F statistics) 2/ }\end{array}$ & 11.39 & (7.03) & 7.19 & $(7.03)$ & 6.31 & $(7.03)$ \\
\hline
\end{tabular}

Note: * significant at 10\%; ${ }^{* *}$ significant at $5 \%$; ${ }^{* * *}$ significant at $1 \%$. Results for control variables (cohort dummies and share of household members for different age categories) are not shown to save space. 1/ Endogeniety test is defined as the difference of two Sargan-Hansen statistics: one for the equation with the smaller set of instruments, where the square of consumption growth and its interacted variable are treated as endogenous, and one for the equation with the larger set of instruments, where the square of consumption growth and its interacted variable are treated as exogenous. 2/ Stock-Yogo weak identification critical value for $10 \%$ maximal IV size is reported in parentheses for the weak identification test.

Figure 1: Number of Children in the Household 


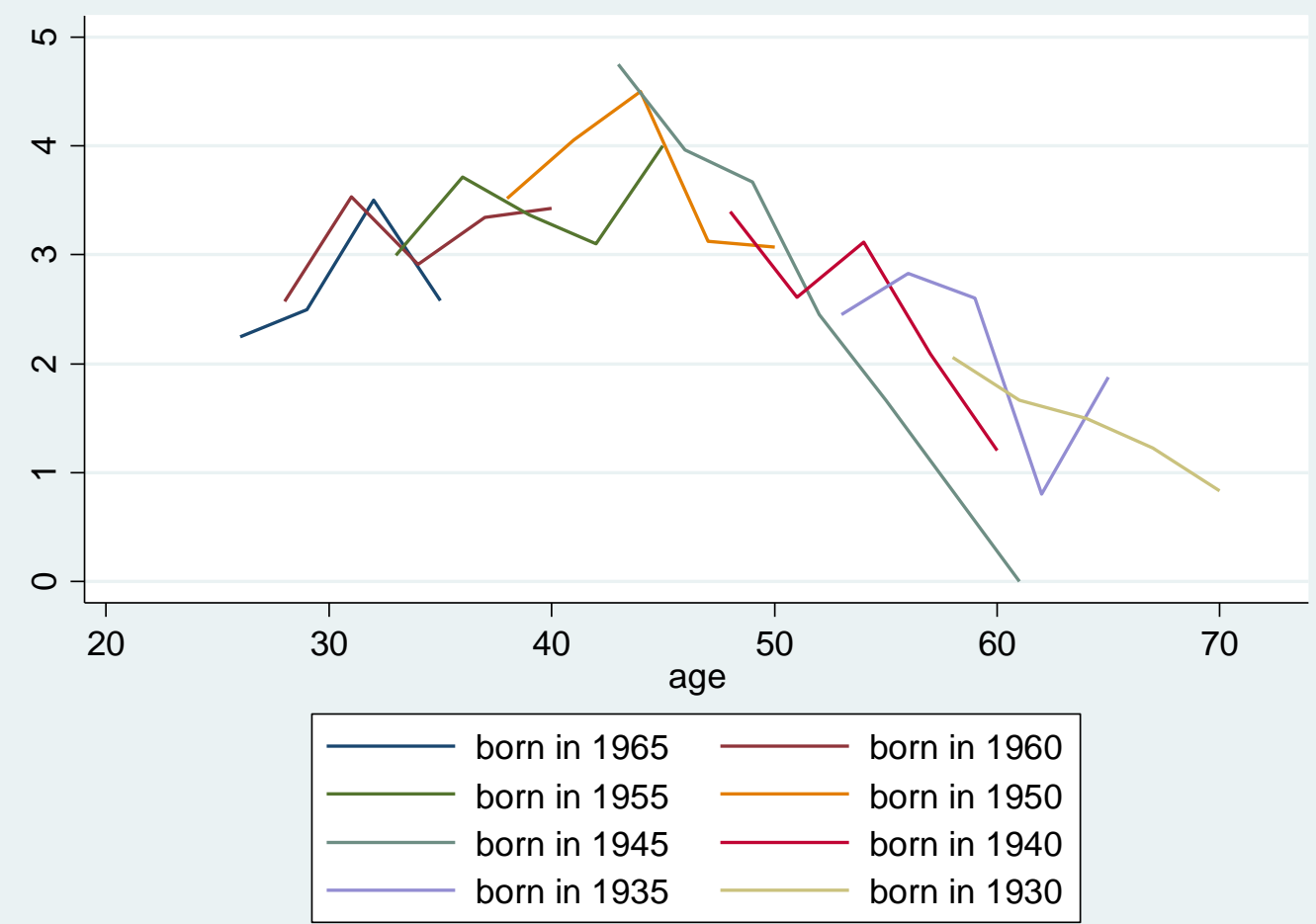

Sources: FIES, author's calculations. 
Figure 2: Mean Income and Consumption for Different Cohorts Over Time

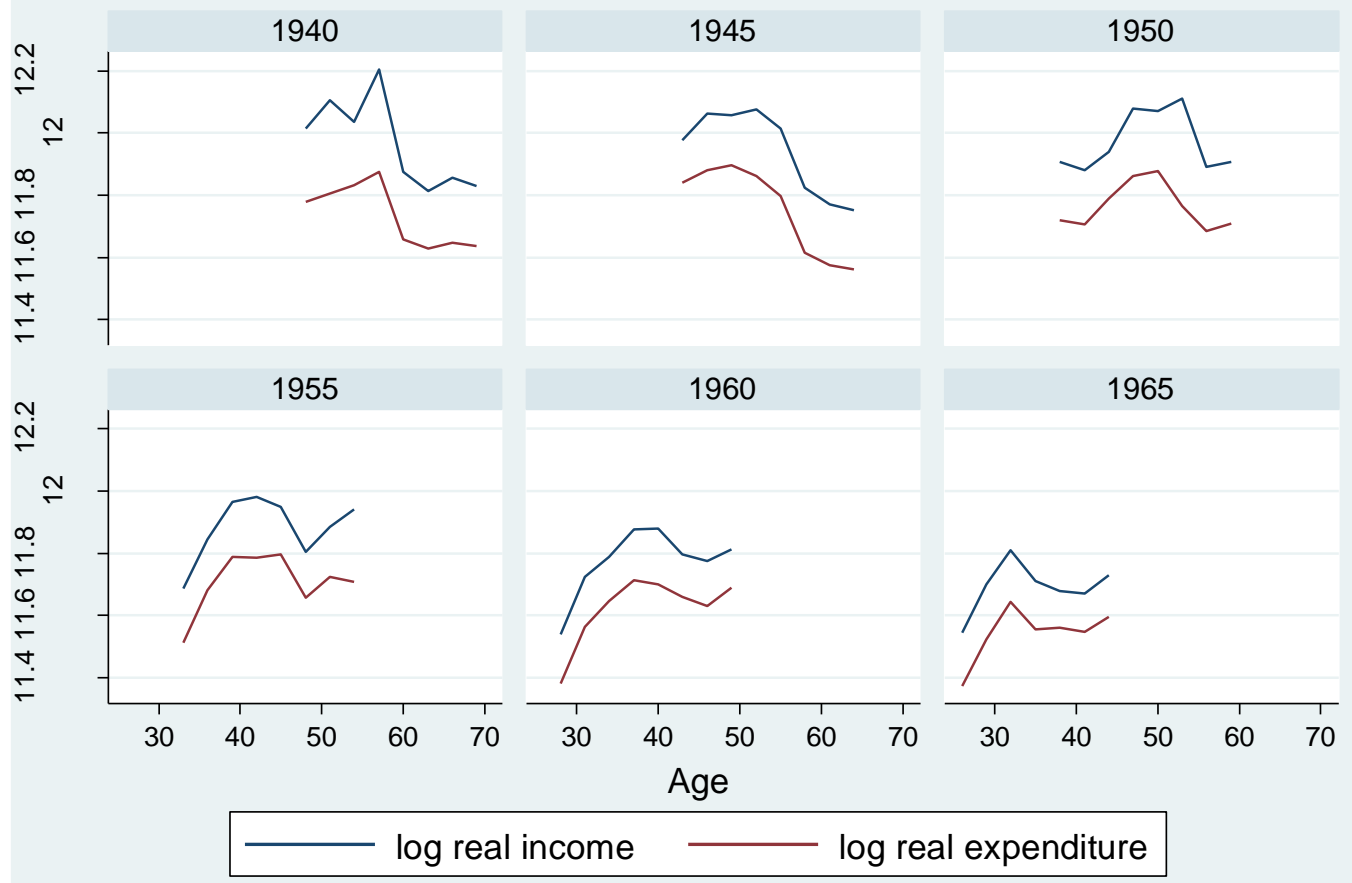

Graphs by =year-age

Sources: FIES, author's calculations. 
Figure 3: Age, Cohort, and Year Effects in Consumption, Income, and Saving

\section{Rates}
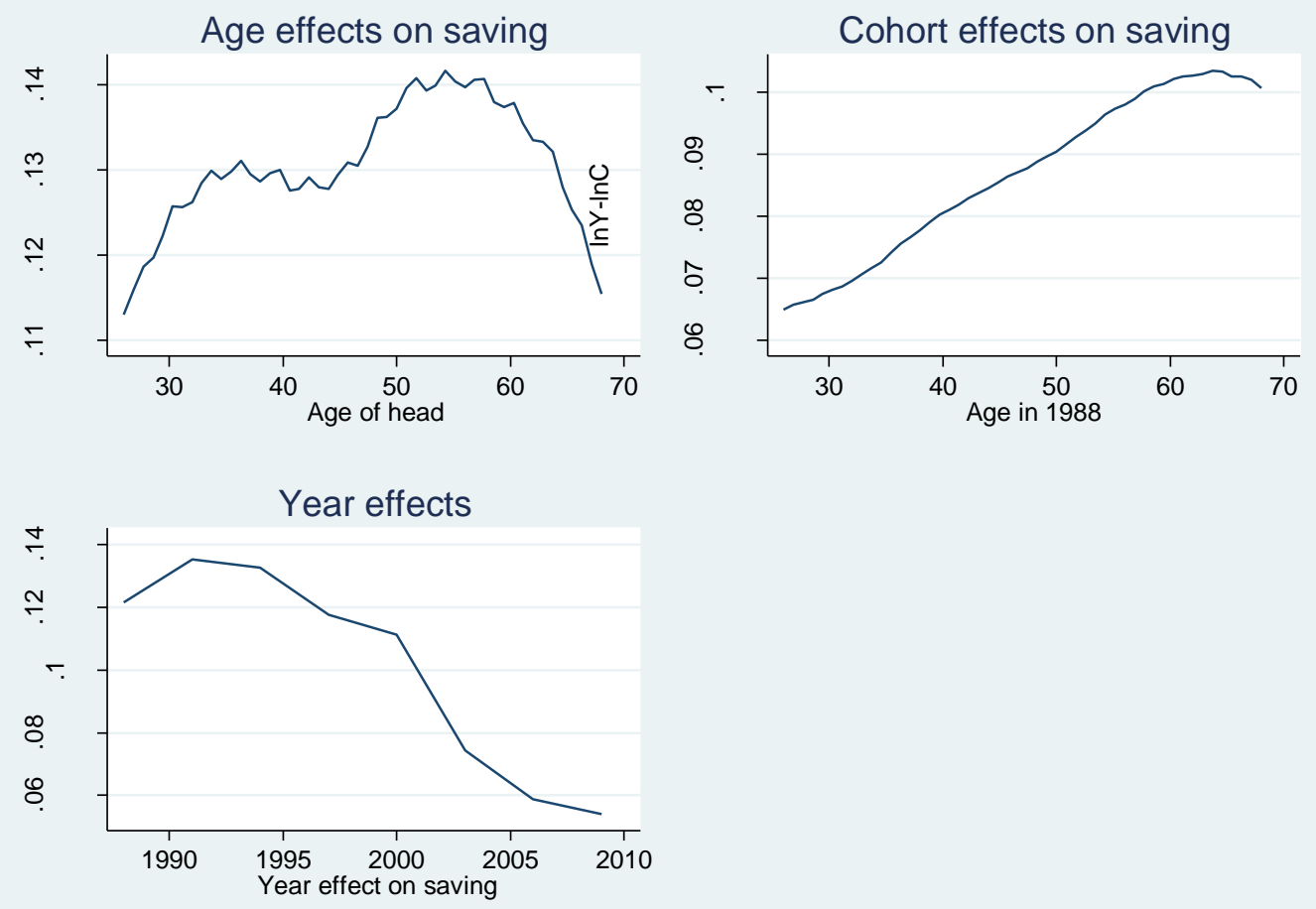

Sources: FIES, author's calculations.

Note: Family size, earners and demographic characteristics are controlled. 
Figure 4: Squared consumption growth by Year

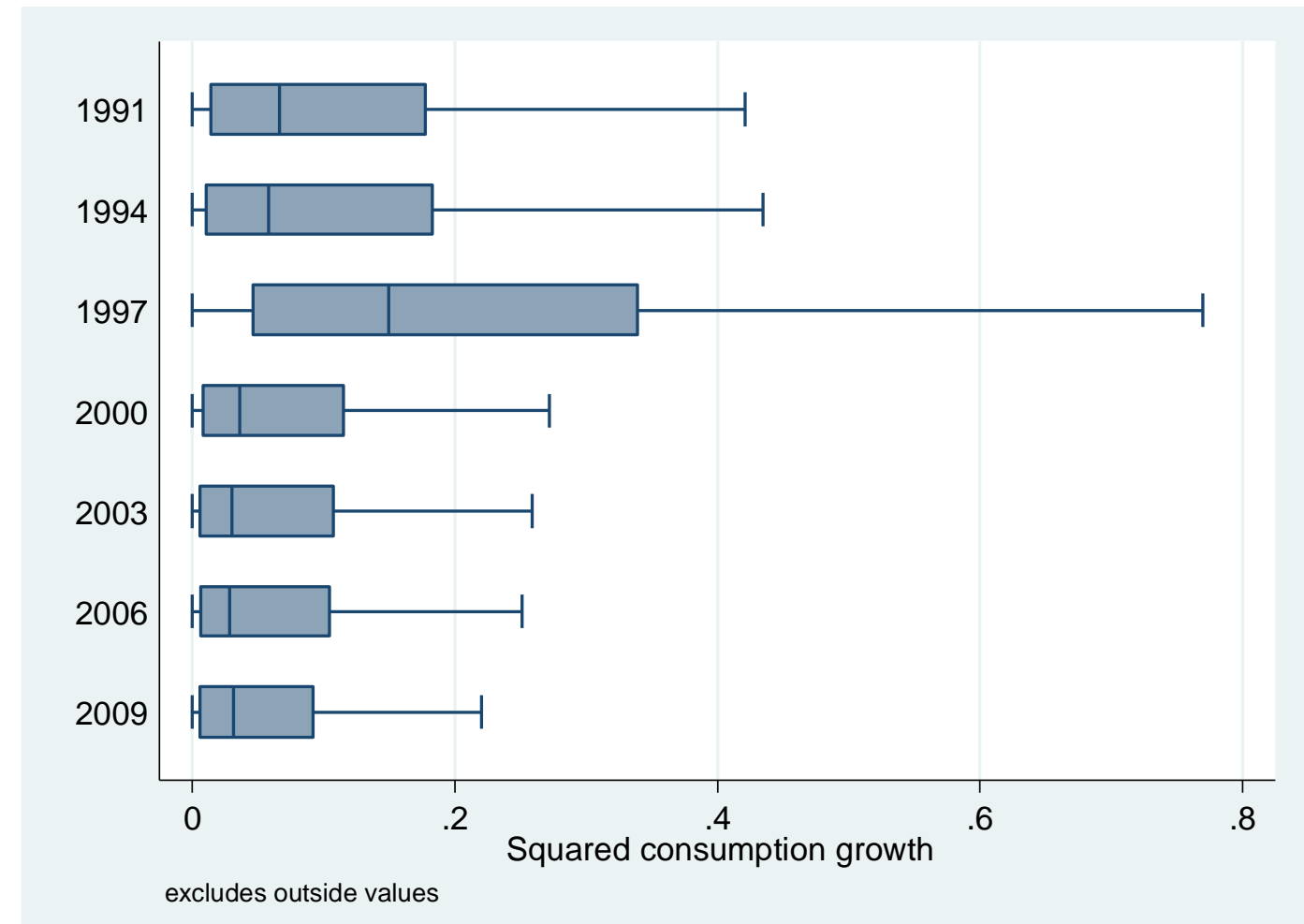

Sources: FIES, author's calculations. 